\title{
Çift Yoğunluklu 1-D Dalgacık Dönüşümü Kullanılarak Parkinson Hastalığının Yaş Faktörüne Göre Tespit Edilmesi
}

\author{
Cüneyt Yücelbaş ${ }^{1 *}$, Şule Yücelbaş ${ }^{2}$ \\ ${ }^{1}$ HakkariÜniversitesi, MühendislikFakültesi, Elektrik-ElektronikMühendisliğiBölümü, Hakkari, Türkiye (ORCID: 0000-0002-4005-6557) \\ ${ }^{2}$ HakkariÜniversitesi, MühendislikFakültesi, Elektrik-ElektronikMühendisliğiBölümü, Hakkari, Türkiye (ORCID: 0000-0002-6758-8502)
}

(İlk GelişTarihi 10 Kasım 2019 ve Kabul Tarihi 7 Aralık 2019)

(DOI: 10.31590/ejosat.649480)

\begin{abstract}
ATIF/REFERENCE: Yücelbaş, C., \& Yücelbaş, Ş. (2019). Çift Yoğunluklu 1-D Dalgacık Dönüşümü Kullanılarak Parkinson Hastalığının Yaş Faktörüne Göre Tespit Edilmesi. Avrupa Bilim ve Teknoloji Dergisi, (17), 881-887.

$\ddot{O} \mathbf{z}$

Parkinson, hareketi etkileyen nörolojik bir sinir sistemi rahatsızlığıdır. Parkinson gibi sinir hücreleriyle yakından ilgisi olan bir hastalığın yürüme verileriyle tespit edilebilmesi muhtemeldir. Günümüzde birçok hastalığa ait belirtiler çok erken yaşlarda ortaya çıkmaya başlamıştır. Bu nedenle bütün hastalıklar için yaş faktörüne göre gerçekleştirilen analiz çalışmaları önem kazanmıştır. Bu sebeple bu çalışmada Çift Yoğunluklu 1-D Dalgacık Dönüşümü (ÇY1DDD) kullanılarak deneklerden elde edilen verilerin yaş faktörüne göre analiz edilmesi ve Parkinson hastalığının $(\mathrm{PH})$ yüksek doğrulukla tespit edilmesi amaçlanmıştır. Kullanılan veri seti genç, yetişkin ve yetişkin hasta olmak üzere 15 denekten alınan yürüyüş verilerinden oluşmaktadır. Kaydedilen veriler üzerinde öncelikle ÇY1DDD yöntemi üç seviye olarak uygulanmış ve yaklaşım (YK) ile detay katsayıları (DK) elde edilmiştir. Daha sonra yaş faktörüne göre elde edilen son seviye YK verilerinden 10 adet özellik çıkarılmıştır. Çıkarılan bu özellikler sağlıklı genç-yetişkin hasta ve sağlıklı yetişkin-yetişkin hasta olmak üzere ikili sınıflar şeklinde 4 farklı karar mekanizmasına verilmiştir. Elde edilen sonuçlar birçok istatistiksel metrikle yorumlanmıştır. Uzman sistemler sayesinde anlamlı sonuçlara ulaşılmış ve genç-sağlıklı verilerinin yetişkin-hasta verilerinden daha düşük hata değerleri ve \%100 sınıflama doğruluğu (SD) oranı ile ayrılabildiği görülmüsstür. Karar mekanizmaları arasında ise sıfıra en yakın hata değerleriyle yapay sinir ağları (YSA), her iki sınıf için de başarısını kanıtlamıştır. Literatürde her ne kadar bu alanda yapılan çalışmalar bulunsa bile, yaş faktörünün PH üzerindeki etkisinin ayrıntılı analizine yeterli derecede yer verilmemesi bu çalışmanın önemini arttırmıştır. Bunun yanında kullanılan etkin özelliklerden bazılarının PH’nin uzman sistemler tarafından otomatik tespit edildiği çalışma alanında daha önce kullanılmamış olması, çalışmanın literatüre katkısını önemli ölçüde desteklemektedir.
\end{abstract}

\section{Detection of Parkinson's disease according to age factor using Double Density 1-D Wavelet Transform}

\begin{abstract}
Parkinson's is a neurological nervous system disorder that affects movement. A disease that is closely related to nerve cells such as Parkinson's is likely to be detected using gait data. Nowadays, symptoms of many diseases start to appear at a very early age. For this reason, analysis studies performed according to age factor for all diseases have gained importance. Therefore, in this study, it was aimed to analyze the data obtained from the subjects according to the age factor by using Double Density 1-D Wavelet Transform (DD1DWT) and to detect Parkinson's disease (PD) with high accuracy. The data set consists of gait data from 15 subjects, young, adult and adult patients. Firstly, DD1DWT method was applied to data in three levels and, the approximation (CA) and detail (CD)
\end{abstract}

*Sorumlu Yazar: Hakkari Üniversitesi, Mühendislik Fakültesi, Elektrik-Elektronik Mühendisliği Bölümü, Hakkari, Türkiye, ORCID: 0000-00024005-6557, cuneytyucelbas@ hakkari.edu.tr 
coefficients were obtained. Afterwards, 10 features were extracted from the last level CA data obtained according to age factor. The extracted features were given to 4 different decision mechanisms in the form of binary classes as healthy young-adult patient and healthy adult-adult patient. The obtained results were interpreted with many statistical metrics. Significant results were obtained through expert systems and it was found that young-healthy data could be distinguished from adult-patient data with lower error values and $100 \%$ classification accuracy rate. ANN has proved its success for both classes with the error values closest to zero among the decision mechanisms. Although there are studies in this field in literature, the lack of adequate analysis of the effect of age factor on PH increased the importance of this study. Furthermore, the fact that some of the effective features used in this study were not used previously in this area where PD was automatically detected by expert systems supports the contribution of the study to the literature.

Keywords: Parkinson, gait signal analysis, double density 1-D wavelet transform, age factor

\section{Giriş}

Nörodejeneratif, psikiyatrik ve gelişim hastalıkları gibi zihinsel bozuklukların, hem kişisel, hem profesyonel hem de sosyal düzeyde psikolojik ve finansal etkileri mutlaka bulunmaktadır. Oluşabilecek bu olumsuz etkiler kişilerin ortalama yaşam süresini azaltır ve yaşam kalitesini düşürür. Bu nedenle bireylerin ve ailelerinin günlük yaşam kalitesi dikkate alınarak bu alana yapılan pozitif katkılar özellikle önemlidir. Bu çalışmanın ortaya çıkmasına temel etki parametresi olarak insani ve sosyal yaşam problemleri gösterilebilir. Çünkü hastalıkların erken teşhisi, bu hastalıkların kişilerin yaşamına olası negatif etkilerini azaltabilir ve hastalık evriminin zamanında kontrol edilmesini sağlayabilir [1]. Erken teşhisi etkileyen etmenler için ise yaş faktörünün hastalıklar ile olan ilişkisinin ayrıntılı analizi gerekli görülmektedir.

Parkinson, beyindeki sinir hücrelerinin kişinin yürüyüş düzenini etkileyen ve "dopamin” olarak bilinen nörotransmitter maddeyi yeterli miktarda üretememesiyle karakterize edilen bir nörodejeneratif hastalıktır [2]. Parkinson gibi nörodejeneratif hastalıkların tanısında fonksiyonel nöro-görüntüleme kullanımı oldukça popüler olmasına rağmen yine de hızlı, kolay ve düşük maliyetli ölçümler sunan alternatif tanı yöntemlerine ihtiyaç duyulmaktadır [2]. Son bulgular serebral korteks, bazal ganglionlar ve omurilik içine inen yolakların insan hareketinde önemli rol oynadığını göstermiştir. Beyin korteksindeki ilgili bölgede oluşabilecek herhangi bir hasarın yürüme şeklini ciddi şekilde etkilemesi muhtemeldir. Bu durum Parkinson gibi sinir hücreleriyle yakından ilgisi olan bir hastalığın yürüme verileriyle tespit edilebilmesi için olumlu bir ortam oluşturmuştur. Dönme aralığı, duruş aralı̆̆ı, adım aralıkları vb. gibi yürüyüş değişkenlerinin ölçümü, ayak tabanındaki kuvvete duyarlı dirençlerle yapılır ve Parkinson hastalığının (PH) teşhisinde hızlı, kolay ve uygun bir ölçüm sağlanabilir [2].

Otomatik tıbbi görüntü işleme ve büyük ölçekli tıbbi veri analizi gibi modern bilgisayar destekli tanıma işlemleri, ilgili tıbbi alanlarda yaygın olarak kullanılmaktadır. Yürüyüş verilerinden PH'nin saptanması için, çekirdek Fisher ayırıcı, saf Bayesian ve destek vektör makinesi gibi makine öğrenme yöntemleri kullanılmış [3-11] ve ümit verici sonuçlar elde edilmiştir. Bununla birlikte, bu yaklaşımlar sadece tipik bir sınıflandırma problemi olarak ele alınmış ve PH'yi yürüyüş bilgilerinden saptamakla birlikte, bu saptamayı anlamlı kılacak veri analizi üzerinde iyi çalışılmamıştır [11]. Bunun yanında literatürde, yaş faktörüne göre PH ve sağlıklıların ayrımının analizi için gerçekleştirilen çalışmalara nadiren rastlanmaktadır [12-14]. Bu çalışmalar veri analizlerini istatistiksel yöntemlerle gerçekleştirmiş olup, bu alanda yapay zekâ yöntemlerinin etkisinin incelenmesine ihtiyaç duyulmaktadır. Bu sebeple, bu çalışmada Çift Yoğunluklu 1-D Dalgacık Dönüşümü (ÇY1DDD) yöntemi kullanılarak deneklerden elde edilen verilerin yaş faktörüne göre analiz edilmesi ve PH'nin yüksek doğrulukla tespit edilmesi amaçlanmıştır. Kullanılan veri seti UCI makine öğrenme deposundan alınmıştır. Bu veri seti genç, yetişkin ve hasta yetişkin olmak üzere 15 denekten alınan yürüyüş verilerden oluşmaktadır [12-14]. Alınan verilere öncelikle ÇY1DDD yöntemi üç seviye olarak uygulanmış ve yaklaşım (YK) ile detay katsayıları (DK) elde edilmiştir. Daha sonra yaş faktörüne göre elde edilen son seviye YK verilerinden 10 adet özellik çıkarılmıştır. Çıkarılan bu özellikler sağlıklı genç-yetişkin hasta ve sağlıklı yetişkin-yetişkin hasta olmak üzere 2li sınıflar şeklinde 4 farklı karar mekanizmasına verilmiştir. Elde edilen sonuçlar birçok istatistiksel metrikle yorumlanmıştır. Sonuç olarak; karar mekanizmaları sayesinde anlamlı sonuçlara ulaşılmış ve genç-sağlıklı verilerinin yetişkin-hasta grubuna göre daha düşük hata değerleri ve \%100 SD oranı ile ayrılabildiği görülmüştür. Karar mekanizmaları arasında ise sıfıra en yakın hata değerleriyle YSA, her iki sınıf için de başarısını kanıtlamıştır. Literatürde her ne kadar bu alanda yapılan çalışmalar çoğunlukta olsa bile, yaş faktörünün PH üzerindeki etkisinin ayrıntılı analizine yeterli derecede yer verilmemesi bu çalışmanın önemini arttırmaktadır. Bunun yanında kullanılan etkin özelliklerin bazılarının bu hastalığın akıllı sistemler tarafından otomatik tespit edildiği çalışma alanı için daha önceden kullanılmamış olması, çalışmanın literatüre katkısını önemli ölçüde desteklemektedir.

\section{Materyal ve Yöntem}

Artan yaşam beklentisi ve nüfusun yaşlanması nedeniyle, PH dünyada daha sık görülen hastalık haline gelmiştir. Bu hastalık; kas kasılması, titreme ve hareketlerin yavaşlığı ile karakterizedir ve genellikle 55 yaşın üzerindeki insanları etkilemektedir. Yürüme, konuşma veya yazmadaki bazı bozulma aşamaları ile motor kontrol sistemlerini etkileyen nörolojik bir hastalıktır [15]. Hastalığın bu belirtilerinden dolayı kişilerin motor hareketlerindeki değişimler kullanılarak otomatik bir şekilde hasta-sağlıklı ayrımı yapılabilir. Bu amaç doğrultusunda çalışma kapsamında kullanılan veri seti [12-14] 15 denekten (5 sağlıklı genç (23 - 29 yaş), 5 sağlıklı yetişkin (71 - 77 yaş) ve 5 yetişkin hasta (60 - 77 yaş)) alınan verilerden oluşmaktadır. Denekler, engelsiz bir yol etrafında ve düz bir zemin üzerinde sürekli yürütülmüşlerdir. Adım aralığı, ayakkabının içine yerleştirilmiş ultra ince, kuvvete duyarlı dirençler kullanılarak ölçülmüştür. Analog kuvvet sinyali 300 Hz'de 12 bitlik bir Analog-Dijital dönüştürücüyle örneklenmiştir. Ayak vuruşları arasındaki süre otomatik olarak hesaplanmıştır. Veriler, sağlıklı deneklerden yaklaşık 15 dakika boyunca kabaca dairesel bir yolda yürütülerek kaydedilmiş olup, Parkinson hastalığı olan deneklerden ise uzun bir koridorda 6 dakika yukarı ve aşağı yürütülerek toplanmıştır [12$14]$. 
Bu çalışmada, hasta ve sağlıklı toplam 15 kişiden alınan yürüyüş verilerine ÇY1DDD yöntemi 3 seviye olarak uygulanmış ve en son seviye sonucunda elde edilen YK verilerinden 10 adet özellik çıkarılmıştır. Çıkarılan özellikler sırasıyla enerji (Denklem-1), ortalama mutlak değer (OMD) (Denklem-2), standart sapma (Std), Std/OMD, eğrilik (çarpıklık) (Denklem-3), basıklık (Denklem-4), hjorth hareketliliği (Denklem-5), hjorth karmaşıklığı (Denklem-6), entropi ve boşluk (clearance) faktörüdür (Denklem-7). Özelliklere ait denklemler aşağıda verilmiştir [16, 17].

$$
\begin{aligned}
& \text { Enerji }=\sqrt{\frac{\sum_{n=1}^{N}\left(X_{n}\right)^{2}}{N}} \\
& O M D=\frac{\sum_{n=1}^{N}\left|X_{n}\right|}{N} \\
& \text { Çarplklık }=\frac{\sum_{n=1}^{N}\left(x(n)-x_{m}\right)^{3}}{(N-1) \sigma_{x}^{3}} \\
& \text { Basıklık }=\frac{\sum_{n=1}^{N}\left(x(n)-x_{m}\right)^{4}}{(N-1) \sigma_{x}^{4}} \\
& \text { Hjorth hareketliliği }=\sqrt{\frac{\operatorname{var}\left(y(t) \frac{d y(t)}{d t}\right)}{\operatorname{var}(y(t))}} \\
& \text { Hjorth karmaşıklığ } \iota=\frac{\operatorname{Hareketlilik}\left(y(t) \frac{d y(t)}{d t}\right)}{\text { Hareketlilik }(y(t))} \\
& \text { Boşluk faktörü }=\frac{X_{\max }}{X_{\text {enerji }}}
\end{aligned}
$$

burada; $X$ veriyi, $N$ veri boyutunu, xm ortalama değeri, $\sigma$ standart sapma değerini, var ( ) varyansı ve $X_{\max }$ verideki maksimum değeri ifade etmektedir.

Bu özelliklere ait veri dağılım grafikleri üç sınıf için de Şekil 1' de gösterilmiştir. Bu grafiklerde mavi renk sağlıklı genç, kırmızı sağlıklı yetişkin ve turkuaz ise hasta yetişkin sınıflarını temsil etmektedir.

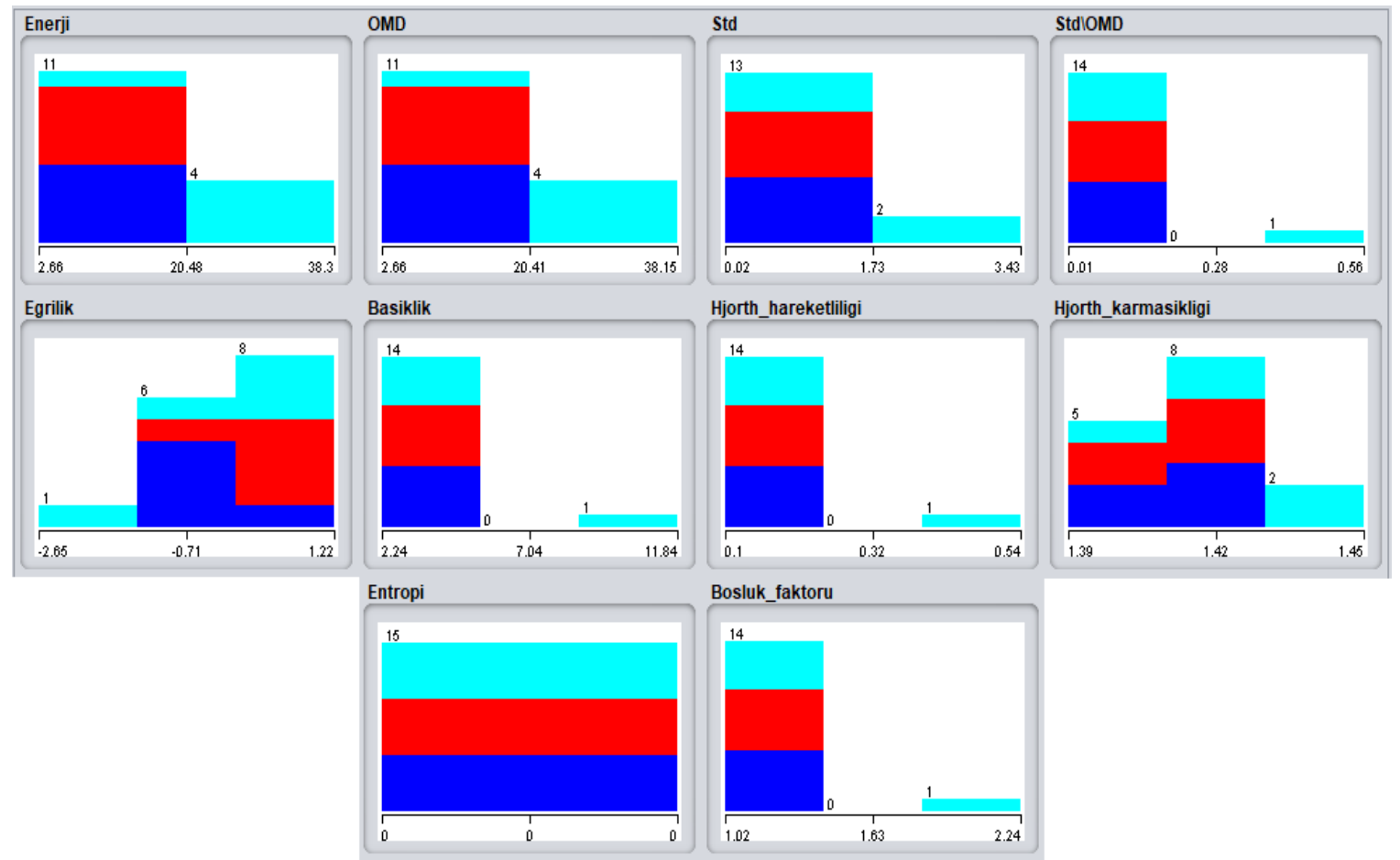

Şekil 1. Özelliklere ait veri dă̆llım grafikleri 
Çıkarılan özelliklerle toplamda, $15 \times 10$ boyutunda veri matrisi elde edilmiştir. Bu verilere 10 kat çapraz doğrulama yöntemi uygulanarak eğitim ve test verileri oluşturulmuştur. Son aşama olarak bu veriler yapay sinir ağları (YSA), rastgele orman (RO), basit lojistik (BL) ve k-en yakın komşu (KEYK) sınıflandırıcılarına sunularak sonuçlar çeşitli istatistiksel metriklerle yorumlanmıştır.

\section{1. Çift Yoğunluklu 1-D Dalgacık Dönüşümü (ÇY1DDD)}

Son zamanlarda ortaya atılmış ve etkinliği ispatlanmış dalgacık dönüşüm yöntemlerinden biri de ÇY1DDD' dir. Veri ayrışımı/indirgenmesi işlemi diğer dönüşüm yöntemlerinde olduğu gibi bunda da filtreler aracılığı ile gerçekleştirilmektedir. ÇY1DDD yönteminde sonlu dürtü yanıtlı filtre bankası kullanılmaktadır. Bu banka içerisinde her seviyede iki yüksek geçiren filttre (YGF) ve bir alçak geçiren filtre (AGF) uygulaması yapılmaktadır [18]. Bu durum Şekil 2' de gerçekleştirilen 3 seviyeli ayrışım uygulamasında görülmektedir. Konu ile ilgili ayrıntılı anlatım araştırmacı Selesnick tarafından verilmiştir [18].

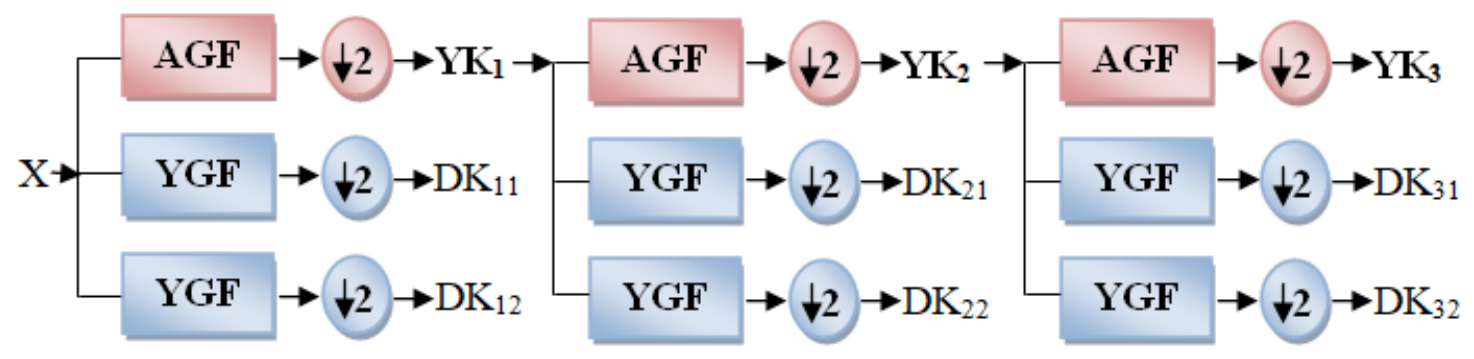

Şekil 2. ÇYIDDD yönteminin üç seviye uygulama grafiği

Çalışma kapsamında 3 seviye ÇY1DDD uygulaması yapılarak son seviye sonucunda elde edilen YK katsayıları ( $\left.\mathrm{YK}_{3}\right)$ kullanılmıştır.

\subsection{Karar Mekanizması ve Performans Metrikleri}

Makine öğrenmesi, üzerinde çalışılan verilerden mantıklı ve rasyonel sonuçlar üretilmesini sağlayan algoritmalar bütünüdür. Bu algoritmaların kullanıldığı uzman sistemler, girdiye uygun çıktı üretebilmekte ve şayet öğretildiyse yorumlayabilmektedir. Bu işlemi uygulanabilir kılan, uzman sistemler içerisine gömülü olan karar verme (sınıflandırma veya kümeleme) mekanizmasıdır. Bu mekanizmanın sınanabilir olması gerçekleştirilen çalışmaların güvenilirliğini arttırmaktadır [19].

Bu amaç doğrultusunda bu çalışmada YSA, RO, BL ve KEYK olmak üzere 4 farklı sınıflandırıcı sistem kullanılmıştır. Bu algoritmaların çalıştıılması ve performans değerlendirmesi Weka 3.8 yazılımı [20] bünyesinde gerçekleştirilmiştir. Bunun yanında, kullanılan veriler genç sağlıklı, yetişkin sağlıklı ve yetişkin hasta olmak üzere 3 farklı sınıf ile etiketlenmiştir. Elde edilen sonuçların yorumlanabilmesi için karmaşıklık (konfüzyon) matrisiyle ortaya konulan doğru pozitif, doğru negatif, yanlış pozitif ve yanlış negatif değerlerinden faydalanılmıştır. İstatistiksel olarak doğru sonuçlar elde edebilmek için ortalama mutlak hata $(O M H)[21,22]$, karekök ortalama hata $(\mathrm{KOH})[21,23]$, göreceli mutlak hata $(G M H)$ [24] ve karekök bağıl hata $(\mathrm{KBH})$ [25] metrikleri kullanılmış ve sirasıyla bu hataların hesapları aşă̆ıdaki denklemler ile gösterilmiştir.

$$
\begin{aligned}
& O M H=\left[\frac{1}{n} \sum_{i=1}^{n}\left|e_{i}\right|\right] \\
& K O H=\sqrt{\left[\frac{1}{n} \sum_{i=1}^{n}\left|e_{i}\right|^{2}\right]} \\
& G M H=\frac{\sqrt{\sum_{i=1}^{n}\left(P_{i}-A_{i}\right)^{2}}}{\sqrt{\sum_{i=1}^{n} A_{i}^{2}}} \\
& K B H=\sqrt{\frac{\sum_{J=1}^{n}\left(P_{i j}-T_{j}\right)^{2}}{\sum_{J=1}^{n}\left(T_{j}-\bar{T}\right)^{2}}} \\
& \bar{T}=\frac{1}{n} \sum_{j=1}^{n} T_{j}
\end{aligned}
$$

Bu denklemlerde $n$ örnek boyutu, e ise hatadır. $A$ gerçek, $P$ ve $P_{i j}$ tahmini değerlerdir. $T_{j}$ ise hedef değerdir. Çalısmalarda bu dört hata değerinin " 0 " veya " 0 "a yakın değerler alması istenir. Bu durum, sınıflara ait verilerin istenildiği şekilde sınıflandırıldığını 
gösterir. Ayrıca, sonuçlar arasındaki uyum, karmaşıklık matrisindeki sonuçlar kullanılarak Kappa ile tespit edilmiştir [26]. Bu değerin "1" e yakın olması, farklı sınıfların verileri arasında mükemmel bir ayrım olduğunu gösterir. Son olarak, sınıflandırma doğruluğu (SD) sonuçları Denklem-12 ile hesaplanmış ve tüm ölçümler değerlendirilmiştir [27, 28].

$$
S D=\frac{\text { Doğru siniflandirllan örnek saylsl }}{\text { Toplamörnek saylst }} \times 100
$$

\section{Deneysel Sonuçlar}

Bu çalışmada genç sağlıklı, yetişkin sağlıklı ve yetişkin hasta sınıflarına ait olmak üzere 15 denekten alınan yürüyüş verileri kullanılmıştır [12-14]. Bu verilere ÇY1DDD yöntemi 3. dereceden uygulanmış ve elde edilen son seviye YK bileşenlerinden 10 farklı özellik çıkarılmıştır. Bu özelliklere 10 kat çapraz doğrulama yöntemi uygulanarak eğitim ve test verileri elde edilmiştir. Daha sonra bu veriler "genç sağlıklı-yetişkin hasta" ve "yetişkin sağlkkl1-yetişkin hasta" olmak üzere gruplanarak 2 sınıflı hale getirilmiş̧ir. Her bir veri grubu ayrı ayrı YSA, RO, BL ve KEYK karar sistemlerine sunularak sonuçlar Tablo 1'de ayrıntılı olarak verilmiştir.

Tablo 1. Veri gruplarının her bir sınıflandırıcı için elde edilen istatistiksel sonuçları (Toplam Örnek Sayısı: TÖS - Doğru Sinıflandırılan Örnek Sayısı: DSÖS)

\begin{tabular}{|c|c|c|c|c|c|c|c|c|c|}
\hline $\begin{array}{c}\text { Veri } \\
\text { Grubu }\end{array}$ & Sinıflandırıcılar & TÖS & DSÖS & Kappa & ОМН & КОН & GMH (\%) & КВН (\%) & SD $(\%)$ \\
\hline \multirow{4}{*}{$\begin{array}{c}\text { Genç } \\
\text { sağlıklı- } \\
\text { Yetişkin } \\
\text { hasta }\end{array}$} & YSA & \multirow{4}{*}{10} & 10 & 1 & 0.0411 & 0.071 & 7.5428 & 13.0156 & 100 \\
\hline & RO & & 9 & 0.8 & 0.115 & 0.2326 & 21.0833 & 42.6462 & 90 \\
\hline & $\mathrm{BL}$ & & 10 & 1 & 0.0836 & 0.1122 & 15.3238 & 20.5713 & 100 \\
\hline & KEYK & & 10 & 1 & 0.0909 & 0.0909 & 16.6667 & 16.6667 & 100 \\
\hline \multirow{4}{*}{$\begin{array}{c}\text { Yetişkin } \\
\text { sağlıklı- } \\
\text { Yetişkin } \\
\text { hasta }\end{array}$} & YSA & \multirow{4}{*}{10} & 10 & 1 & 0.0483 & 0.0962 & 8.8559 & 17.6285 & 100 \\
\hline & RO & & 9 & 0.8 & 0.129 & 0.2376 & 23.65 & 43.5585 & 90 \\
\hline & BL & & 10 & 1 & 0.0928 & 0.1239 & 17.013 & 22.7165 & 100 \\
\hline & KEYK & & 10 & 1 & 0.0909 & 0.0909 & 16.6667 & 16.6667 & 100 \\
\hline
\end{tabular}

Tablo 1'e göre, her iki veri grubu için tüm sistemler arasında en iyi sonuçlara YSA ile ulaşılmış̧ır. Sonuç olarak, toplam 10 girdi doğru olarak sınıflandırılmış ve \% 100 SD oranı elde edilmiştir. Ayrıca, Kappa değeri "1" e ulaşmış ve belirlenen sınıflar arasında mükemmel ayrışma sağlanmıştır. YSA karar sistemi için $\mathrm{OMH}, \mathrm{KOH}, \mathrm{GMH}$ ve $\mathrm{KBH}$ hata değerleri diğer sistemlere göre " 0 " değerine daha çok yaklaşarak bu sistemin hatasıza yakın bir ayrıştırma yaptığını kanıtlamıştır. KEYK sistemi her iki veri grubu için de $\% 100$ SD oranı ve "1" Kappa katsayısı değerine ulaşmıştır. Ayrıca bu sisteme ait OMH, KOH, GMH ve KBH hata değerleri için her iki veri grubunda da aynı sonuçlar elde edilmiştir. RO karar sistemi ise tüm sistemler arasında en kötü performansı göstermiştir. Bu algoritma ile tüm istatistiksel metriklerde en düşük sonuçlar elde edilmiştir. Bu sinıflandırıcı, veri setindeki 10 girdinin 9'unu doğru sınıflandırabilmiş ve yetişkin sağlıkl1-yetişkin hasta veri grubuna ait bir veriyi diğer veri grubuna aitmiş gibi değerlendirmiştir. Bunun sonucunda \%90 SD oranı ve " 0.8 " Kappa değeri elde edilmiştir. Gruplara göre tüm karar sistemleri için elde edilen GMH ve KBH sonuçlarının grafiksel dağılımı Şekil 3'de gösterilmiştir. Buradan anlaşılacağı üzere en başarısız sistem RO iken, genel olarak en düşük hata değerlerinin alınarak en başarılı performansın elde edildiği karar sistemi YSA olmuştur.

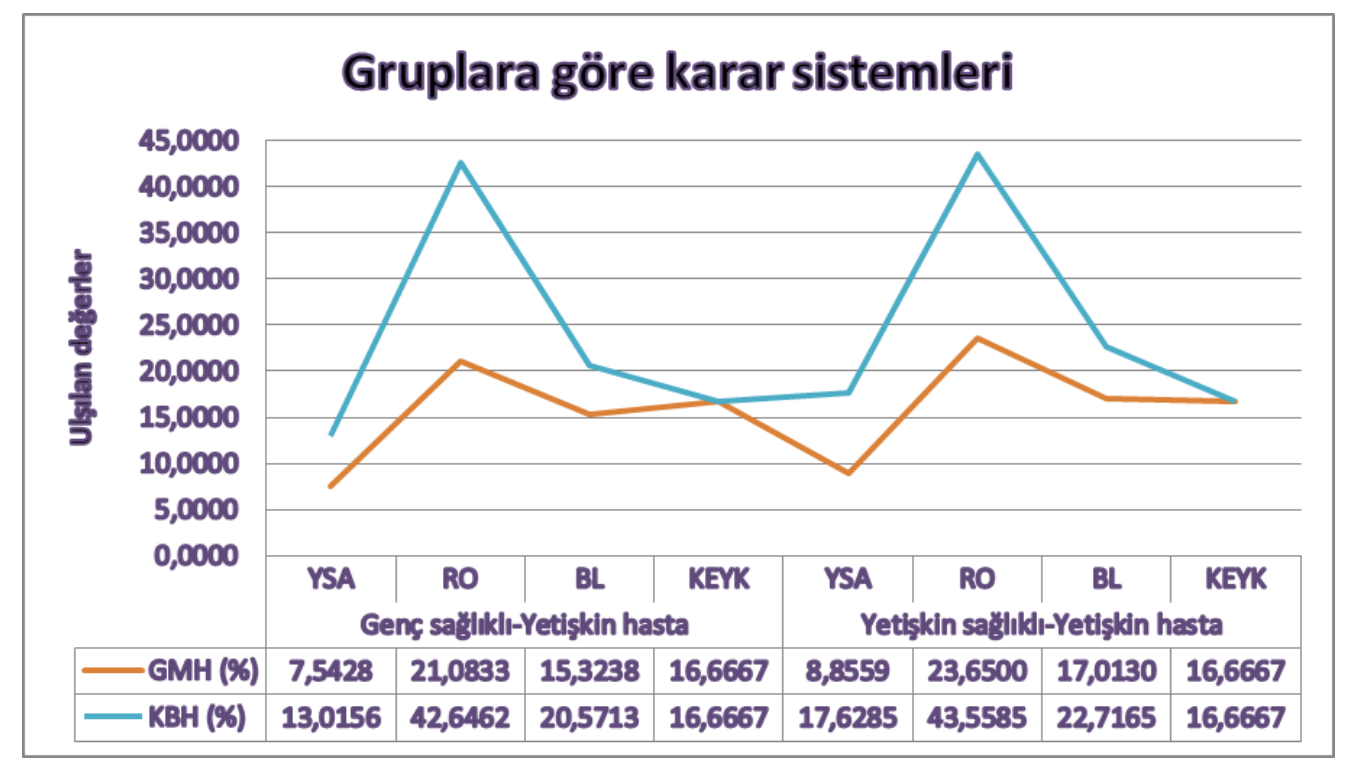

Şekil 3. Gruplara göre tüm karar sistemleri için elde edilen \% GMH ve \% KBH sonuçlart 


\section{Sonuç ve Tartışma}

Parkinson, hareketi etkileyen ilerleyici bir sinir sistemi bozukluğudur. Bu hastalığa ait belirtiler bazen zor fark edilebilen bir titreme başlayabilir. Bu hastalıkta titreme yaygındır ve bu durum sık sık hareket sertliğine veya yavaşlamasına neden olur. PH'nin erken evrelerinde, hastanın yüz mimiklerinde belirsizleşmeler ortaya çıkabilir. Bunun yanında yürürken kolların sallanmaması ve konuşmanın yumuşak veya bulanık olması da diğer belirtilerdendir. PH genel olarak 40 yaş üstü kişilerde daha sık karşılaşılan bir rahatsızlıktır [29]. Fakat günümüzde birçok hastalığa ait belirtiler literatürde belirtilenden daha erken yaşlarda ortaya çıkmaya başlamıştır. $\mathrm{Bu}$ nedenle bütün hastalıklar için yaş faktörüne göre gerçekleştirilen analiz çalışmaları önem kazanmaktadır. Bunun yanında, günümüzde yapay zekâ teknolojisine göre geliştirilen hastalık tespit sistemleri, kişilerin hastalıklar için ön değerlendirme yapmasına olanak sağlamıştır. Bu durum zaman ile mekândan bağımsız olmayı kolaylaştırmış ve uzmanların yaptıkları işlerin doğruluğunu test edebilmeleri için zemin oluşturmuştur. Belirtilen amaçlar doğrultusunda bu çalışmada, yaş faktörüne göre elde edilen girdilerin değerlendirilmesi sonucunda PH veya sağlıklı olarak karar verme kapasitesine sahip otomatik bir analiz sistemi önerilmiştir. Çalışma kapsamında yaş faktörünün PH hastalığı için etkisini analiz edebilmek için sağlıklı denekler yaş aralıklarına göre sınıflandırılmıştır. Önerilen karar mekanizmalarında verilerin ayırt ediciliğini arttırabilmek ve daha güvenilir sonuçlar elde edebilmek için deneklerden alınan yürüyüş verilerine öncelikle ÇY1DDD yöntemi uygulanmıştır. Daha sonra, bu yöntem 3. Seviye sonucunda elde edilen YK'dan zaman ortamında etkin 10 adet özellik çıkarılmıştır. Karar mekanizması için 4 farklı sınıflandırıcı sistem belirlenmiş ve son veri seti yaş faktörüne göre bu sistemlere sunulmuştur. Bu sunum sonucunda, karar mekanizmaları sayesinde anlamlı sonuçlara ulaşılmış ve genç-sağlıklı sınıfının yetişkin-hasta sınıfından daha düşük hata değerleri ve \%100 SD oranı ile ayrılabildiği görülmüştür. Karar mekanizmaları arasında ise sıfıra en yakın $\mathrm{OMH}$ ve $\mathrm{KOH}$ hata değerleriyle YSA, her iki sınıf için de başarısını kanıtlamıştır. Elde edilen sonuçlar, genç bireylerde ortaya çıkabilecek PH' nin yetişkinlere göre daha net bir şekilde erken teşhis edilebileceğini göstermiştir.

Literatürde her ne kadar bu alanda yapılan çalışmalar çoğunlukta olsa bile yaş faktörünün PH üzerindeki etkisinin ayrıntılı analizine yeterli derecede yer verilmemiştir. Bunun yanında, PH' nin tespiti için ÇY1DDD yöntemi ile özellik analizinin yapıldığı bir çalışmaya rastlanılmamıştır. Ayrıca kullanılan etkin özelliklerin bazıları, bu hastalığın uzman sistemler tarafından otomatik teşhis edildiği çalışma alanı için yenidir. Bu sebeple gerçekleştirilen çalışmanın literatüre katkısı önemli ölçüdedir. Bu çalışma baz alınarak ve veri sayısı genişletilerek daha farklı yaş grupları için ayrıntılı analizler yapılabilir. Böylece daha fazla yaş grubunun bu hastalıkla olan ilişkisi ortaya konulmuş olacaktır.

\section{Kaynakça}

[1] D. Braga, A. M. Madureira, L. Coelho, \& R. Ajith. (2019). Automatic detection of Parkinson's disease based on acoustic analysis of speech. Engineering Applications of Artificial Intelligence, vol. 77, pp. 148-158.

[2] D. Joshi, A. Khajuria, \& P. Joshi. (2017). An automatic non-invasive method for Parkinson's disease classification. Computer methods and programs in biomedicine, vol. 145, pp. 135-145.

[3] F. Wahid, R. K. Begg, C. J. Hass, S. Halgamuge, \& D. C. Ackland. (2015). Classification of Parkinson's disease gait using spatialtemporal gait features. IEEE journal of biomedical and health informatics, vol. 19, no. 6, pp. 1794-1802.

[4] J. Hannink et al. 2016. Stride length estimation with deep learning. arXiv preprint arXiv:1609.03321.

[5] T. Khan \& J. Westin. (2011). Motion cues analysis for Parkinson gait recognition. in 15th International Congress of Parkinson's Disease and Movement Disorders, Toronto, Canada, 5-9 juni, 2011.

[6] J. D. A. Paredes, B. Muñoz, W. Agredo, Y. Ariza-Araújo, J. L. Orozco, \& A. Navarro. (2015). A reliability assessment software using Kinect to complement the clinical evaluation of Parkinson's disease. in 2015 37th Annual International Conference of the IEEE Engineering in Medicine and Biology Society (EMBC): IEEE, pp. 6860-6863.

[7] A. P. Rocha, H. Choupina, J. M. Fernandes, M. J. Rosas, R. Vaz, \& J. P. S. Cunha. (2015). Kinect v2 based system for Parkinson's disease assessment. in 2015 37th Annual International Conference of the IEEE Engineering in Medicine and Biology Society $(E M B C):$ IEEE, pp. 1279-1282.

[8] A. P. Rocha, H. Choupina, J. M. Fernandes, M. J. Rosas, R. Vaz, \& J. P. S. Cunha. (2014). Parkinson's disease assessment based on gait analysis using an innovative RGB-D camera system. in 2014 36th Annual International Conference of the IEEE Engineering in Medicine and Biology Society: IEEE, pp. 3126-3129.

[9] H.-L. Chen, G. Wang, C. Ma, Z.-N. Cai, W.-B. Liu, \& S.-J. Wang. (2016). An efficient hybrid kernel extreme learning machine approach for early diagnosis of Parkinson' s disease. Neurocomputing, vol. 184, pp. 131-144.

[10] D. Rodriguez-Martin, A. Samà, C. Pérez-López, J. Cabestany, A. Català, \& A. Rodríguez-Molinero. (2015). Posture transition identification on PD patients through a SVM-based technique and a single waist-worn accelerometer. Neurocomputing, vol. 164, pp. 144-153.

[11] A. Zhao, L. Qi, J. Li, J. Dong, \& H. Yu. (2018). A hybrid spatio-temporal model for detection and severity rating of Parkinson's Disease from gait data. Neurocomputing, vol. 315, pp. 1-8.

[12] J. M. Hausdorff, P. L. Purdon, C. Peng, Z. Ladin, J. Y. Wei, \& A. L. Goldberger. (1996). Fractal dynamics of human gait: stability of long-range correlations in stride interval fluctuations. Journal of applied physiology, vol. 80, no. 5, pp. 1448-1457 https://physionet.org/content/gaitdb/1.0.0/.

[13] J. M. Hausdorff et al. (1997). Altered fractal dynamics of gait: reduced stride-interval correlations with aging and Huntington's disease. Journal of applied physiology, vol. 82, no. 1, pp. 262-269.

[14] J. M. Hausdorff, M. E. Cudkowicz, R. Firtion, J. Y. Wei, \& A. L. Goldberger. (1998). Gait variability and basal ganglia disorders: stride-to-stride variations of gait cycle timing in Parkinson's disease and Huntington's disease. Movement disorders, vol. 13, no. 3, pp. 428-437.

e-ISSN: $2148-2683$ 
[15] A. Jilbab, A. Benba, \& A. Hammouch. (2017). Quantification system of Parkinson's disease. International Journal of Speech Technology, vol. 20, no. 1, pp. 143-150.

[16] S. Yucelbas, S. Ozsen, C. Yucelbas, G. Tezel, S. Kuccukturk, \& S. Yosunkaya. (2016). Effect of EEG time domain features on the classification of sleep stages. Indian J. Sci. Technol, vol. 9, no. 25, pp. 1-8.

[17] P. Careena, M. M. S. J. Preetha, \& P. Arun. (2019). Research on Murmur from Time Domain Features of Heart Sounds. International Journal of Recent Technology and Engineering (IJRTE), vol. 8, no. 1S4, pp. 736-743.

[18] I. W. Selesnick. (2001). The double density DWT. inWavelets in Signal and Image Analysis: Springer, pp. 39-66.

[19] C. M. Bishop. (2006). Pattern recognition and machine learning. New York, NY: Springer, 738 p.

[20] I. H. Witten, E. Frank, L. E. Trigg, M. A. Hall, G. Holmes, \& S. J. Cunningham. (1999). Weka: Practical machine learning tools and techniques with Java implementations.

[21] C. J. Willmott \& K. Matsuura. (2005). Advantages of the mean absolute error (MAE) over the root mean square error (RMSE) in assessing average model performance. Climate research, vol. 30, no. 1, pp. 79-82.

[22] F. Yildiz, \& A.T. Özdemir. (2019). Prediction of laser-induced thermal damage with artificial neural networks. Laser Phys., 29 (7), $7 \mathrm{pp}$.

[23] F. Yıldız. (2019). 1940 Nm Fiber Lazer Kaynağının Karaciğer Dokusundaki Isıl Hasarının Yapay Sinir Ağları İle Tahmini. Uludağ University Journal of The Faculty of Engineering, 24 (2), 583-594.

[24] P. Cichosz. (2015). Data mining algorithms: explained using R. Wiley Online Library.

[25] Gepsoft. (2019). Analyzing GeneXproTools Models Statistically - Root Relative Squared Error (Access date: 10 September 2019) https://www.gepsoft.com/gxpt4kb/Chapter10/Section1/SS07.htm. .

[26] J. R. Landis \& G. G. Koch. (1977). An application of hierarchical kappa-type statistics in the assessment of majority agreement among multiple observers. Biometrics, pp. 363-374.

[27] Ş. Yücelbaş, C. Yücelbaş, G. Tezel, S. Özşen, S. Küççüktürk, \& Ş. Yosunkaya. (2017). Pre-determination of OSA degree using morphological features of the ECG signal. Expert Systems with Applications, vol. 81, pp. 79-87.

[28] F. Yildiz. (2019). Optimization of an artificial neural network to estimate laser ablation efficiency. Laser Phys., 29 (11), 7 pp.

[29] H. Apaydın, S. Özekmekçi, S. Ŏguz, \& İ. Zileli. (2013). Parkinson Hastalığı Hasta Ve Yakınları İçin El Kitabı. http://parkinsondernegi.com/wp-content/uploads/2017/04/Parkinson-Hastaligi-Hasta-ve-Yakinlari-icin-El-Kitabi.pdf," İstanbul. 